\title{
Exhaled nitric oxide measurements with dynamic flow restriction in children aged 4-8 yrs
}

\author{
M.W.H. Pijnenburg*, E.T. Lissenberg*, W. Hofhuis*, L. Ghiro", W.C.J. Hop ${ }^{\star}$, W.P. Holland ${ }^{+}$, \\ J.C. de Jongste*
}

Exhaled nitric oxide measurements with dynamic flow restriction in children aged 4-8 yrs. M.W.H. Pijnenburg, E.T. Lissenberg, W. Hofhuis, L. Ghiro, W.C.J. Hop, W.P. Holland, J.C. de Jongste. C ERS Journals Ltd 2002.

ABSTRACT: Fractional exhaled nitric oxide concentration (FENO) depends on exhalation flow; however, children often are unable to perform controlled flow procedures. Therefore, a device was developed for off-line FENO sampling, with dynamic flow restriction (DFR).

The authors compared off-line with on-line FENO, assessed feasibility, and obtained normal values for FENO in children aged 4-8 yrs. Subjects inhaled nitric oxide (NO)free air and exhaled into the device, where DFR kept exhalation flow constant at $50 \mathrm{~mL} \cdot \mathrm{s}^{-1}$. Dead space air was discarded. Exhaled air was collected in a $150 \mathrm{~mL}$ mylar balloon. On-line measurements were performed and values compared with off-line FENO in 19 adult volunteers. Seventy-nine children performed off-line sampling. All samples were analysed with a chemiluminescence NO-analyser. Normal values were obtained in 34 healthy children.

There was an excellent correlation between on- and off-line values. Bland and Altman plots showed good agreement between on- and off-line FENO. Seventy-four out of 79 children were able to perform a correct off-line procedure. Geometric mean \pm SEM FENO in healthy children was $4.9 \pm 1.2$ parts per billion (ppb) for male children and $7.6 \pm 1.1 \mathrm{ppb}$ for female children.

It can be concluded that off-line fraction of exhaled nitric oxide measurements with dynamic flow restriction are feasible in young children and correspond to on-line values. Eur Respir J 2002; 20: 919-924.

\begin{abstract}
*Dept of Paediatrics/Respiratory Medicine, Dept of Epidemiology and Biostatistics, ${ }^{+}$Central Instrumentation Dept, Erasmus MC University Medical Center - Sophia Children's Hospital, Rotterdam, The Netherlands. " Dept of Paediatrics/Respiratory Medicine, University Hospital Padova, Padova, Italy.

Correspondence: J.C. de Jongste, Erasmus Medical Center - Sophia Children's Hospital, P.O. Box 2060, 3000 CB Rotterdam, The Netherlands.

Fax: 31 104636801

E-mail: dejongste@lons.azr.nl
\end{abstract}

Keywords: Children, dynamic flow restriction, exhaled nitric oxide, normal values, off-line, on-line

Received: February 152002 Accepted after revision: May 312002

M.W.H. Pijnenburg was supported by a grant from the Dutch Asthma Foundation and L. Ghiro was supported by a grant of the Italian Nitric Oxide Club (INOC).
Fractional exhaled nitric oxide concentration (FENO) is a noninvasive marker of eosinophilic airway inflammation in asthma [1,2]. The American Thoracic Society (ATS) published guidelines for the sampling of FENO in adults and older children [3]. In addition, a joint European Respiratory Society (ERS)/ATS task force on exhaled nitric oxide (NO) measurements in children has summarised its recommendations [4].

FENo values are highly dependent on exhalation flow [5]. Hence, ATS guidelines recommend measurements during a single, slow exhalation with constant, low flow. However, 4-8-yr-old children are often unable to perform the required controlled flow procedures needed for standardised sampling [6,7]. In children unable to cooperate, tidal breathing methods or exhalations with uncontrolled flow have been used, but these are ill standardised and allow for contamination with ambient and nasal NO [3]. A dynamic flow restrictor (DFR) that automatically varies resistance depending on blowing pressure overcomes these problems. The ERS/ATS Task Force 2001 is the first to give recommendations on measuring FENO in children, and it mentions DFR as a method of choice [4]. However, published data on DFR concern techniques where manual adjustments are made and this limits their applicability. Especially in young children, FENO as a noninvasive, simple, reproducible inflammatory marker would be very useful as a diagnostic and monitoring tool in respiratory disease. Therefore, the authors developed a new, flow-constant device for off-line measurement of FENO in children aged $\geqslant 4$ yrs, who can cooperate but have difficulty in performing controlled expiratory manoeuvres. In the present study, the authors first validated the device against on-line FENO in young adult volunteers. Next, FEno was measured in schoolchildren aged $4-8$ yrs in order to assess feasibility and obtain normal values.

\section{Subjects and methods}

\section{Subjects}

The off-line technique was validated in 19 adult volunteers, selected to provide a wide range of FENO. 
Children aged 4-8 yrs were recruited from a primary school. The parents of 86 out of 125 children gave written informed consent for their children to participate in the study. All parents completed a modified, validated International Study of Asthma and Allergies in Childhood (ISAAC) questionnaire about wheezing, rhinitis and eczema [8]. Questions about parental smoking, recent colds and use of medication were added. For 1 week, a diary card on respiratory symptoms and use of medication was completed. Height and weight were measured. The study was approved by the Medical Ethical Committee of the Erasmus MC/Sophia Children's Hospital.

\section{Off-line exhaled nitric oxide measurements}

Exhaled air was collected with a new, custom-built device, which contained a mechanical variable flow restrictor that kept exhalation flow constant at $50 \mathrm{~mL} \cdot \mathrm{s}^{-1}$ over a pressure range of $5-20 \mathrm{cmH}_{2} \mathrm{O}$ (fig. 1). Preliminary experiments with calibration gas of 115 parts per billion (ppb) indicated that the device was NO inert. Subjects were asked to take a deep breath through a mouthpiece attached to a bag with NO-free medical air via a nonrebreathing valve. They immediately exhaled into the DFR. A manometer checked mouth pressure and manoeuvres were accepted when pressures were $5-10 \mathrm{cmH}_{2} \mathrm{O}$. A whistling feedback signal indicated a pressure of $>5 \mathrm{cmH}_{2} \mathrm{O}$. The dead space air of the subject and device was discarded by a side tube. Air exhaled during the last 3-4 s was collected in a $150 \mathrm{~mL}$ NOimpermeable mylar balloon (Jurjen de Vries BV, Leeuwarden, the Netherlands). Total duration of the measurement was $\sim 10 \mathrm{~s}$. All subjects performed five manoeuvres with a varying exhalation time, discarding exhaled air during 3, 4, 6, 8 and 10 s corresponding to $150-500 \mathrm{~mL}$, in random order. Between measurements, there was a minimum of $30 \mathrm{~s}$ rest. All balloons were sealed, and analysed within $2 \mathrm{~h}$.

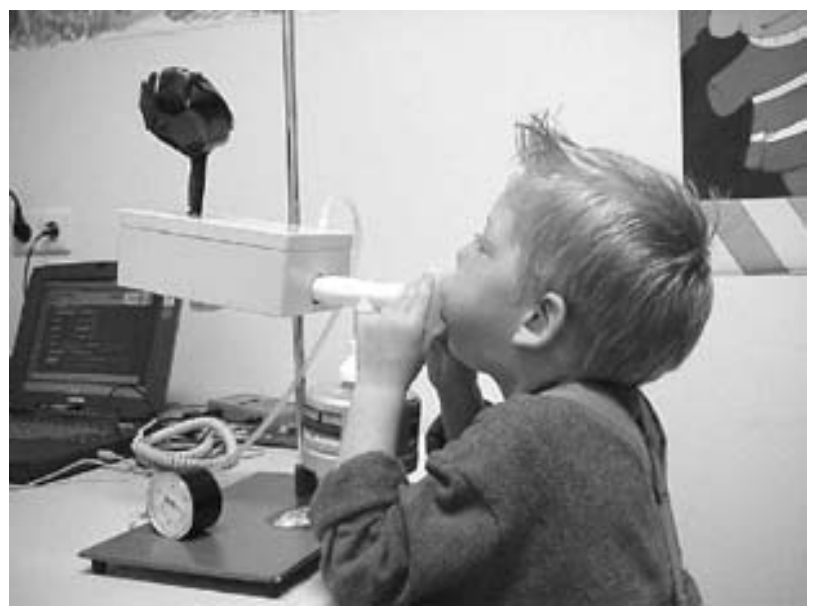

Fig. 1.-A 4-yr-old male performing the single-breath off-line procedure for fractional exhaled nitric oxide concentration measurement with dynamic flow restriction (published with permission from BARALDI and DE JONGSTE [4]).
Samples of ambient air were collected and analysed. A chemiluminescence analyser (Sievers 280 NOA, Boulder, CO, USA) with a sensitivity of $<0.1 \mathrm{ppb}$ and a detection range of $<0.1-500,000 \mathrm{ppb}$ was used for measuring NO. The analyser was checked once daily before the measurements, using certified NO-free gas and certified $115 \mathrm{ppb}$ gas (BOC, Herenthout, Belgium). The sampling flow was $200 \mathrm{~mL} \cdot \mathrm{min}^{-1}$ and the response time was $200 \mathrm{~ms}$.

\section{On-line exhaled nitric oxide measurements}

Three on-line manoeuvres were performed on the NIOX NO-analyser (Aerocrine, Stockholm, Sweden) according to ATS guidelines [3]. Subjects inspired NO-free air and exhaled for a minimum of $7 \mathrm{~s}$. A FENO plateau of $\geqslant 3 \mathrm{~s}$ was required to approve the measurement. Exhalation flow was kept constant through visual feedback and a DFR at $50 \mathrm{~mL} \cdot \mathrm{s}^{-1}$. Mouth pressure was checked.

\section{Off-line exhaled nitric oxide measurements in children}

Exhaled air was collected while children attended school, during the morning hours of 1 week. The first $4 \mathrm{~s}$ of exhaled air $(200 \mathrm{~mL})$ were discarded, thus the total duration of the measurement was $\sim 7 \mathrm{~s}$. All balloons were analysed within $6 \mathrm{~h}$, a period in which NO stays stable in balloons [9]. Samples of ambient air were collected every hour.

\section{Data analysis}

The method of Bland and Altman [10] was used to assess reproducibility of duplicate measurements and agreement between off-line and on-line values. For correlations between FENO and diary card data, age, height, sex and ambient NO-values, bivariate correlations analysis was used (Pearson's correlation coefficient). Data are presented as geometric means (log transformed, processed and backtransformed) and standard error of the mean \pm sem. The level of significance was set at $\mathrm{p}=0.05$.

\section{Results}

\section{Validation of off-line device}

Nineteen subjects (seven male) with a mean age of 29.5 yrs (range 21.9-39.5 yrs) participated. Geometric mean FENo was $21.9 \mathrm{ppb}(6.0-109.6)$ for on-line values and $20.0 \mathrm{ppb}(7.6-79.6)$ for off-line values, with $150 \mathrm{~mL}$ discarded dead space volume. With higher discarded volumes off-line, FENO was similar (table 1). There was an excellent correlation between on- and off-line values, irrespective of the discarded dead space volume. Pearson correlation coefficients varied between 0.95-0.98 $(\mathrm{p}<0.001)$ (table 1). BLAND and Altman [10] plots for agreement between on- and 
Table 1. -Effect of discarded dead space volume on offline fractional exhaled nitric oxide concentration (FENO) and correlation with on-line values

\begin{tabular}{ccccc}
\hline & $\begin{array}{c}\text { Discarded } \\
\text { volume } \\
\mathrm{mL}\end{array}$ & $\begin{array}{c}\mathrm{FENO}^{\#} \\
\mathrm{ppb}\end{array}$ & $\begin{array}{c}\text { Pearson } \\
\mathrm{r}^{\Uparrow}\end{array}$ & $\begin{array}{c}\text { Mean } \pm \mathrm{sD} \\
\text { difference } \\
\text { on-/off-line } \\
\mathrm{ppb}\end{array}$ \\
\hline On-line & - & 21.9 & - & - \\
Off-line & & & & \\
$3 \mathrm{~s}$ & 150 & 20.0 & 0.95 & $1.1 \pm 1.3$ \\
$4 \mathrm{~s}$ & 200 & 20.9 & 0.96 & $1.0 \pm 1.3$ \\
$6 \mathrm{~s}$ & 300 & 21.9 & 0.97 & $1.0 \pm 1.2$ \\
$8 \mathrm{~s}$ & 400 & 21.9 & 0.98 & $1.0 \pm 1.2$ \\
$10 \mathrm{~s}$ & 500 & 21.7 & 0.98 & $1.0 \pm 1.2$ \\
\hline
\end{tabular}

\#: Geometric mean FENO; ${ }^{\top}$ : Pearson correlation coefficient for on-line and off-line values. $n=19$.

off-line values for discarded volumes of 200 and $500 \mathrm{~mL}$ are shown in figure 2 .

\section{Off-line measurements in children}

Eighty-six children entered the study, but five children were excluded because they could not perform the manoeuvres (mean age 57 months, range 50-64 months). Two children were absent during the days of the measurements. Hence, data were obtained from 79 children (46 male, 33 female) with a mean age of 67 months (range 44-89 months) (table 2). Symptom scores were low; only one child had a symptom score $>7$ and $73 \%$ had a symptom score of 0 . There was no correlation between FENO values and diary card scores or between any of the individual questions of the ISAAC questionnaire and FENO. No correlation was found between FENO and age or height. However, the authors found significantly higher FENO values in female compared with male children. Geometric mean values were $5.0 \pm 1.1 \mathrm{ppb}$ for males and $6.9 \pm 1.1 \mathrm{ppb}$ for females $(\mathrm{p}=0.006)$. Male and female children did not differ in height, age or symptom scores (table 2).

\section{Ambient air and exhaled nitric oxide}

Ambient NO levels were low and varied between 0.0-19.9 ppb, median $3.7 \mathrm{ppb}$. Despite the inhalation of NO-free air, a significant correlation between FENO and ambient $\mathrm{NO}$ was found $(\mathrm{r}=0.529, \mathrm{p}<0.001)$. Every $10 \mathrm{ppb}$ elevation of ambient air resulted in a $2.1 \mathrm{ppb}$
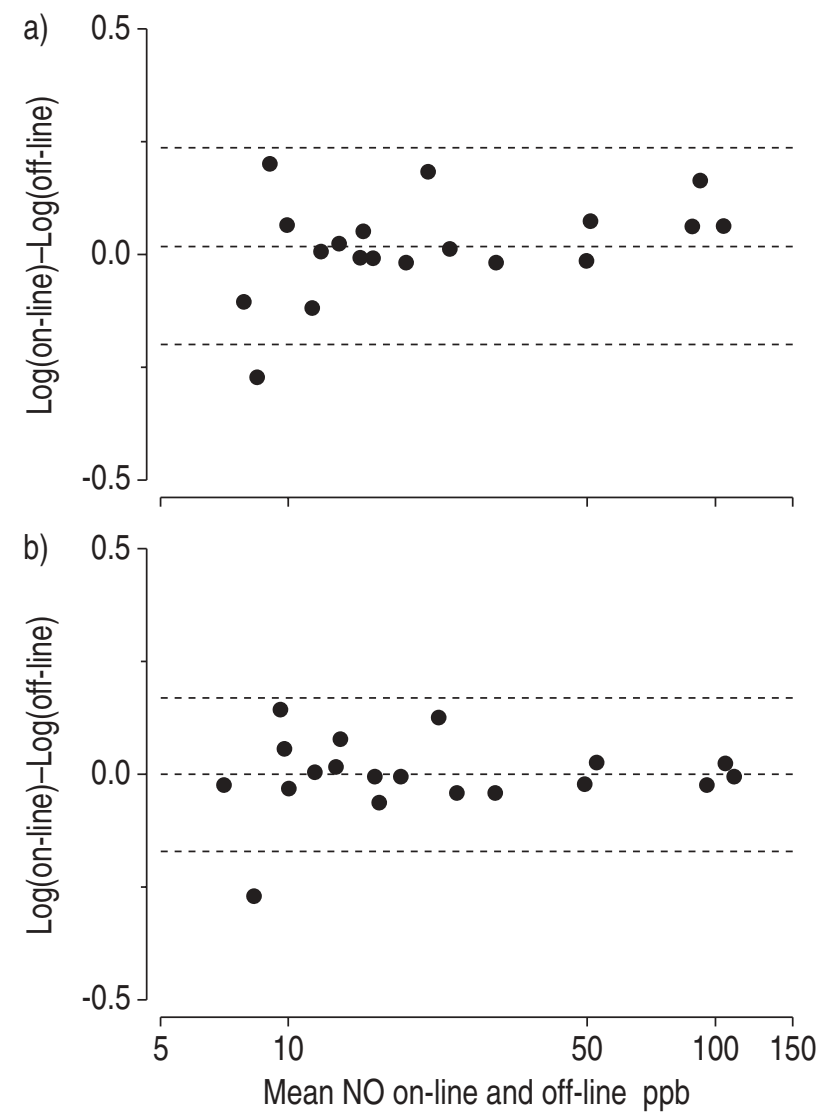

Fig. 2.-BLAND and ALTMAN [10] analysis of agreement between off-line and on-line fractional exhaled nitric oxide concentration values in adults after discarding a) $200(4 \mathrm{~s})$ and b) $500(10 \mathrm{~s}) \mathrm{mL}$ of air. NO: nitric oxide. Dashed lines indicate $\pm 2 \mathrm{SD}$.

increase in FENO. No correlation was found between FENO and ambient NO $<7 \mathrm{ppb}$.

\section{Duplicate measurements}

BLAND and Altman [10] analysis showed no difference and a high reproducibility of duplicate measurements (fig. 3). The intraclass correlation coefficient was 0.84 .

\section{Normal values}

Thirty-four children (20 males) had a negative ISAAC questionnaire for asthma and allergy, did

Table 2.-Data for the study population

\begin{tabular}{lccc}
\hline & Whole group & Male $^{+}$ & Female $^{\S}$ \\
\hline FENO ppb & $5.8 \pm 1.1$ & $5.0 \pm 1.1$ & $6.9 \pm 1.1^{\#}$ \\
Age months & $68(44-89)$ & $67(44-84)$ & $71(52-89)$ \\
Weight kg & $20.6(15.1-31.3)$ & $20.5(16.6-31.3)$ & $20.9(15.1-30.3)$ \\
Height cm & $117.0(105.3-130.9)$ & $115.3(107.0-129.5)$ & $119.2(105.3-130.9)$ \\
Symptom scores & $0.0(0-105)$ & $0.0(0-105)$ & $0.0(0-7)$ \\
\hline Data are presented as median (range) or geometric mean \pm SEM. FENO: fractional exhaled nitric oxide concentration. ${ }^{\top}: \mathrm{n}=79 ;$ \\
${ }^{+}: \mathrm{n}=46 ;$; $: \mathrm{n}=33 ;{ }^{\#}: \mathrm{p}=0.006$.
\end{tabular}




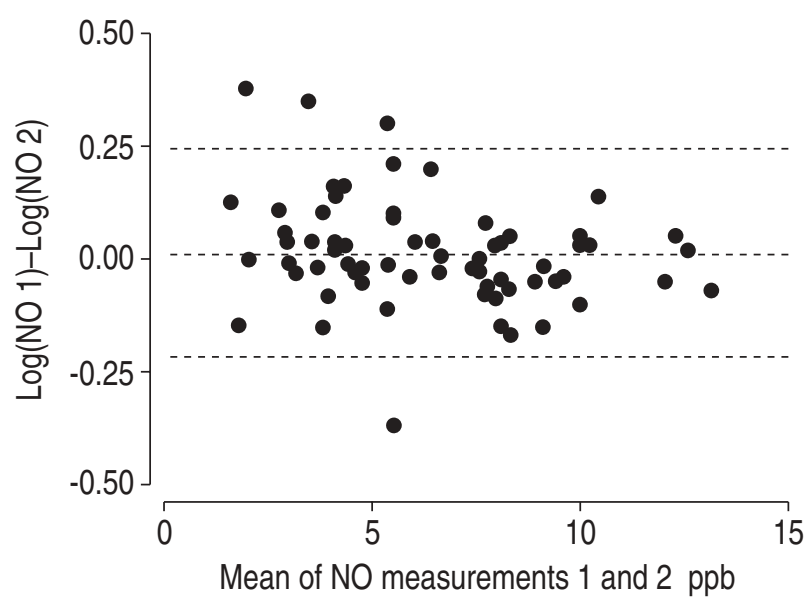

Fig. 3.-BLAND and ALTMAN [10] analysis of agreement between duplicate fractional exhaled nitric oxide concentration values. NO: nitric oxide. Dashed lines indicate \pm 2 SD.

not have any airway symptoms and were steroid naive. These children were used to determine normal values. Their mean age was 69 months (range 52-84 months). Geometric mean FENO was $4.9 \pm 1.2 \mathrm{ppb}$ for males and 7.6 $\pm 1.1 \mathrm{ppb}$ for females $(\mathrm{p}=0.02)$. There was no correlation between age, weight or height and FENO.

\section{Discussion}

The authors found an excellent correlation between on-line values and FENO obtained off-line employing DFR. In addition, there was good agreement between the two methods. Increasing the volume of discarded dead space air did not improve agreement. Reproducibility of duplicate off-line measurements was good.

Correlations of different on- and off-line sampling techniques have been reported in the literature [7, 11-14]. Several authors found an excellent correlation between on- and off-line values; however, agreement between both methods differed in different studies. While SiLkoff et al. [12] found lower off-line values compared to on-line values, PAREDI et al. [11] found that agreement was flow dependent and best with expiratory flows of $\sim 150 \mathrm{~mL} \cdot \mathrm{s}^{-1}$. At the recommended expiratory flow of $50 \mathrm{~mL} \cdot \mathrm{s}^{-1}$, these authors found low agreement. In contrast, the present findings show that with a single-breath, low-flow exhalation according to ATS guidelines, controlled by dynamic flow restriction and discarding dead space air, both good correlation and agreement between on- and off-line values can be obtained. As the NIOX NO-analyser (Aerocrine) works with DFR as well, this finding is not surprising.

Several groups described different off-line techniques for sampling exhaled NO [7, 11-19]. These include tidal breathing techniques and uncontrolled or controlled single exhalations into a reservoir. Tidal breathing techniques require no active cooperation and are feasible down to the newborn age. On the other hand, exhalation flow cannot easily be controlled and it is difficult to prevent nasal contamination adequately, leading to increased variation in FENO values. Uncontrolled single exhalations against a resistance are easy to perform and reproducible even in young children, and there is no need for expensive or complicated equipment $[7,14,16]$. However, in the absence of flow control, FENo values may vary and be unsuitable to monitor individual patients. Controlled single exhalation manoeuvres improve reproducibility and agreement with on-line procedures. Biofeedback signals can be used to facilitate the procedure. Nevertheless, many young children will still have difficulty in performing these manoeuvres. Dynamic flow restriction overcomes this problem. The majority of all children in the present study successfully completed the sampling procedure with the off-line device with dynamic flow restriction. Hence, it is now feasible to obtain reliable FENO values at a constant, low flow in children aged $\geqslant 4$ yrs, using a simple mechanical sampling device.

The present data are the first on 4-8-yr-old children, measured with a constant flow of $50 \mathrm{~mL} \cdot \mathrm{s}^{-1}$. Although the number of children was relatively small, the values found are in agreement with values from previous studies in older children [9, 15, 20]. Moreover, symptom scores in the whole study population were low, and FENO values in children with and without symptoms were not significantly different. This suggests that, in this young age group, airway symptoms are less likely to be related to eosinophilic airway inflammation than in older subjects, thus confirming earlier observations [21]. Future studies using larger groups should establish reference values.

The authors found significantly higher FENO values in female compared to male children. Only in one previous study was a difference in FENO between males and females found. However, in this study higher FENO levels as well as higher plasma nitrate levels were found in males [22]. Male and female children in the present study did not differ in weight, height or age. Female children were not expected to have a higher prevalence of atopy or mild asthma and symptom scores did not differ between males and females $(p=0.48)[23,24]$. As atopy was not measured specifically, a difference in atopic status between males and females may still be possible in this relatively small sample. The authors could not confirm the correlation between age and FENO that was reported for older children, nor was a correlation with height found [9].

No correlation between diary card symptom score or questionnaire answers and FENO was shown. However, symptom scores in the authors' group (measured in summer) were very low, and only four children were treated for respiratory symptoms with inhaled steroids. Therefore, lack of correlation may be due to the relatively healthy population that was included.

The authors found a significant correlation between FENO and ambient NO levels $>7 \mathrm{ppb}$. Several studies investigated the correlation between FENO and ambient NO using different sampling techniques, resulting in conflicting data [25-27]. Ambient air can have NO values as high as several hundred $\mathrm{ppb}$ and may 
contaminate dead space of the airways, thus giving false high FENO values after expiration in a reservoir. Inspiration of NO-free air or discarding dead space air have been proposed as methods to eliminate this disturbing factor [3]. However, despite these measures, the authors still found a correlation between FENO and ambient NO. Several explanations for the present findings are possible. According to ATS recommendations, children took only one deep breath of NO free air, which may be not enough to effectively wash out dead space NO. Although special attention was paid to closure of the mouth around the mouthpiece during inspiration, some children may have inhaled ambient air along the mouthpiece. Based on the authors' findings in adult volunteers where agreement did not improve with higher discarded volumes, the first $150-200 \mathrm{~mL}$ of each exhalation was discarded before exhaled air was sampled. Because the anatomical dead space of children is smaller than in adults, discarding this amount of exhaled air should be sufficient to avoid contamination with dead space air. The low FENo in these healthy children may reveal any contamination more readily than higher levels in asthmatics. The authors recommend to record ambient NO levels when measuring FENO.

In conclusion, the authors found an excellent agreement and correlation between on- and off-line fractional exhaled nitric oxide values, with a new constant low-flow off-line device for single-breath measurement with dynamic flow restriction. With this device, fractional exhaled nitric oxide can be reproducibly measured in children aged $4-8$ yrs, with a high success rate. Normal fractional exhaled nitric oxide values for healthy male and female children are reported. Furthermore, there was a weak correlation between ambient nitric oxide $>7$ parts per billion and fractional exhaled nitric oxide levels, despite the inhalation of nitric oxide-free air and dead space discarding. Thus, the authors propose this off-line technique and dynamic flow restriction as a suitable method to collect samples for fractional exhaled nitric oxide measurements in children too young to cooperate with recommended on-line procedures.

\footnotetext{
Acknowledgements. The authors are indebted to the children and the teachers of the St Michaël School in Rotterdam, who enthusiastically participated in this study.
}

\section{References}

1. Kharitonov SA, Yates D, Robbins RA, LoganSinclair R, Shinebourne EA, Barnes PJ. Increased nitric oxide in exhaled air of asthmatic patients. Lancet 1994; 343: 133-135.

2. Barnes PJ, Kharitonov SA. Exhaled nitric oxide: a new lung function test. Thorax 1996; 51: 233-237.

3. Recommendations for Standardized Procedures for the Online and Off-line Measurement of Exhaled Lower Respiratory Nitric Oxide and Nasal Nitric
Oxide in Adults and Children - 1999. Am J Respir Crit Care Med 1999; 160: 2104-2117.

4. Baraldi E, de Jongste JC. Measurement of exhaled nitric oxide in children, 2001. ERS/ATS Statement. Eur Respir J 2002; 20: 223-237.

5. Kroesbergen A, Jöbsis Q, Bel EH, Hop WC, de Jongste JC. Flow-dependency of exhaled nitric oxide in children with asthma and cystic fibrosis. Eur Respir $J$ 1999; 14: 871-875.

6. Baraldi E, Scollo M, Zaramella C, Zanconato S, Zacchello F. A simple flow-driven method for online measurement of exhaled NO starting at the age of 4 to 5 years. Am J Respir Crit Care Med 2000; 162: $1828-1832$.

7. Jöbsis Q, Schellekens SL, Kroesbergen A, Hop WC, de Jongste JC. Sampling of exhaled nitric oxide in children: end-expiratory plateau, balloon and tidal breathing methods compared. Eur Respir J 1999; 13: 1406-1410.

8. Asher MI, Keil U, Anderson HR, et al. International Study of Asthma and Allergies in Childhood (ISAAC): rationale and methods. Eur Respir J 1995; 8: 483-491.

9. Jöbsis Q, Raatgeep HC, Hop WC, de Jongste JC. Controlled low flow off line sampling of exhaled nitric oxide in children. Thorax 2001; 56: 285-289.

10. Bland JM, Altman DG. Statistical methods for assessing agreement between two methods of clinical measurement. Lancet 1986; 1: 307-310.

11. Paredi P, Loukides S, Ward S, et al. Exhalation flow and pressure-controlled reservoir collection of exhaled nitric oxide for remote and delayed analysis. Thorax 1998; 53: 775-779.

12. Silkoff PE, Stevens A, Pak J, Bucher-Bartelson B, Martin RJ. A method for the standardized offline collection of exhaled nitric oxide. Chest 1999; 116 : 754-759.

13. Kissoon N, Duckworth LJ, Blake KV, Murphy SP, Taylor CL, Silkoff PE. FE(NO): relationship to exhalation rates and online versus bag collection in healthy adolescents. Am J Respir Crit Care Med 2000; 162: 539-545.

14. Canady RG, Platts-Mills T, Murphy A, Johannesen R, Gaston B. Vital capacity reservoir and online measurement of childhood nitrosopnea are linearly related. Am J Respir Crit Care Med 1999; 159: 311314.

15. Baraldi E, Azzolin NM, Cracco A, Zacchello F. Reference values of exhaled nitric oxide for healthy children 6-15 years old. Pediatr Pulmonol 1999; 27: 54-58.

16. Nelson BV, Sears S, Woods J, et al. Expired nitric oxide as a marker for childhood asthma. $J$ Pediatr 1997; 130: 423-427.

17. Jöbsis Q, Raatgeep HC, Hop WCJ, De Jongste JC. Controlled low flow offline sampling of exhaled nitric oxide in children. Thorax 2001; 56: 285-289.

18. Jöbsis Q, Schellekens SL, Kroesbergen A, Hop WC, de Jongste JC. Off-line sampling of exhaled air for nitric oxide measurement in children: methodological aspects. Eur Respir J 2001; 17: 898-903.

19. Baraldi E, Dario C, Ongaro R, et al. Exhaled nitric oxide concentrations during treatment of wheezing exacerbation in infants and young children. $\mathrm{Am}$ J Respir Crit Care Med 1999; 159: 1284-1288.

20. Daniel PF, Klug B, Valerius NH. Collection and measurement of exhaled nitric oxide in young children 
during tidal breathing. Eur Respir J 2001; 18: Suppl. 33, 38s.

21. Fitch PS, Brown V, Schock BC, Taylor R, Ennis M, Shields MD. Chronic cough in children: bronchoalveolar lavage findings. Eur Respir J 2000; 16: 11091114.

22. Jilma B, Kastner J, Mensik C, et al. Sex differences in concentrations of exhaled nitric oxide and plasma nitrate. Life Sci 1996; 58: 469-476.

23. Martinez FD, Wright AL, Taussig LM, Holberg CJ, Halonen M, Morgan WJ. Asthma and wheezing in the first six years of life. The Group Health Medical Associates. N Engl J Med 1995; 332: 133-138.

24. Sears MR, Burrows B, Flannery EM, Herbison GP, Holdaway MD. Atopy in childhood. I. Gender and allergen related risks for development of hay fever and asthma. Clin Exp Allergy 1993; 23: 941948.

25. Baraldi E, Azzolin NM, Dario C, et al. Effect of atmospheric nitric oxide (NO) on measurements of exhaled NO in asthmatic children. Pediatr Pulmonol 1998; 26: 30-34.

26. Piacentini GL, Bodini A, Vino L, et al. Influence of environmental concentrations of NO on the exhaled NO test. Am J Respir Crit Care Med 1998; 158: 1299 1301.

27. Therminarias A, Flore P, Favre-Juvin A, Oddou MF, Delaire M, Grimbert F. Air contamination with nitric oxide: effect on exhaled nitric oxide response. $\mathrm{Am}$ J Respir Crit Care Med 1998; 157: 791-795. 